\title{
Bounding ahead with our Journal
}

\section{Savvas Andronikou MB BCh, FCRad (SA), FRCR (Lond), $P h D$ (UCT) \\ Department of Radiology Tygerberg Hospital University of Stellenbosch}

This will read more like a memo than an editorial but I guess this is the best avenue for informing our readers. We must extend our gratitude as a Society and as a professional body to Ian Duncan who served this journal as chief editor and brought it alive. I see Ian is still active in publishing, with a current paper in Paediatric Radiology. Keep up the good work Ian and we hope we can continue your impetus to improve the journal.

This will be the first issue with the editorial team changes. I have taken over duties of chief editor and I have brought in Mala Modi and Nicky Wieselthaler as assistant editors because of their publication experience. We hope to bring some variety and enthusiasm working as a team. The journal has also undergone a minor face-lift as you can see. We have changed to a smaller more 'professional' font and will use the space for larger images, seeing that this is an imaging journal. You will also notice a new but small section called the specialty corner at the back of each issue. This will be managed by the assistant editors and hopefully will highlight subspecialty expertise that exists nationwide. The one in this issue concentrates for obvious reasons on paediatric radiology and is produced by PISSA (Paediatric Imaging Society of South Africa), a subgroup of the Radiological Society of South Africa. We hope that the other subgroups that exist will take up the reins using our first contribution as a template to deliver news, journal article reviews and conference information regarding their subspecialty.

Congratulations must go to the contributing universities for their issues to date. In particular you will notice that this issue is formed primarily from 'spillover' from the previous Wits issue, which shows the enthusiasm and desire to get down and publish. Some words of warning must accompany this, however. In their eagerness some contributors ignored regular methodology and referencing requirements that make a journal what it is and that differentiate it from a periodical. I have also noted an increasing amount of long-winded case reports rather than solid research or review material. Case reports should be truncated into pictorial interludes where the picture tells the story. Review articles are essential for a worthwhile read and for educational purposes but they should be written by someone with insight into the topic of interest. Publication of MMed theses is encouraged as this will add significantly to the journal content quality.

We have redesigned the instructions to authors indicating the types of articles acceptable for publication and giving a description of each. We have also decided on a restriction in article length to encourage concise work and to create more topics per journal issue. These will be available on the RSSA website. Our editorial team will be involved in accepting or rejecting submissions which will be delivered via the guest editor from each university. The schedule for 2006 will also be announced on the RSSA website. I hope you will enjoy our input as we move towards a peer-reviewed publication that is cited on the major databases.

\section{Savvas Andronikou Chief Editor}

